\title{
GESTÃO DO TRABALHO E ORGANIZAÇÃO COLETIVA DE TRABALHADORES DO SETOR PÚBLICO DE SAÚDE
}

\author{
WORK MANAGEMENT AND COLLECTIVE ORGANIZATION OF HEALTH PUBLIC SECTOR WORKERS \\ GESTIÓN DEL TRABAJO Y ORGANIZACIÓN COLECTIVA DE TRABAJADORES DEL SECTOR PÚBLICO \\ DE SALUD
}

Leonardo Dresch Eberhardt ${ }^{1}$

Manoela de Carvalho ${ }^{2}$

Resumo O tema da organização coletiva é uma dimensão importante imbricada na gestão do trabalho em saúde e na saúde do trabalhador. Este artigo analisa a trajetória do movimento de trabalhadores dos serviços municipais de saúde de Cascavel, cidade do estado do Paraná, Brasil, no enfrentamento de questões relacionadas ao trabalho e à gestão do trabalho. Utilizou-se a metodologia qualitativa, com a realização de entrevistas semiestruturadas e técnica de bola-de-neve para a definição da amostra. Os resultados indicam que os trabalhadores se organizaram coletivamente, no período analisado, por meio de reuniões periódicas, da fundação de um sindicato e da realização de greves e mobilizações. No entanto, diante dos embates com a gestão municipal, alguns adoeceram e outros optaram por formas individuais de resistência. O sindicato dos servidores municipais da saúde, fundado em 1988, passou de uma atuação combativa para a cooperação com a gestão na década de 2000. Conclui-se que, baseados nas dificuldades descritas, cabe aos trabalhadores do setor público de saúde de Cascavel o desafio de refletirem sobre o passado e continuarem buscando construir estratégias coletivas de organização que defendam seus interesses frente à gestão.

Palavras-chave trabalhadores; saúde do trabalhador; pessoal de saúde; administração de recursos humanos em saúde.
Abstract The theme of collective organization is an important dimension imbricated in health work management and occupational health. In this article we analyze the trajectory of workers of municipal health services in Cascavel, Paraná, Brazil, in addressing issues related to work and work management. We used the qualitative methodology, with the application of semi-structured interviews and snowball technique for defining the sample. The results show that workers organized collectively through regular meetings, the foundation of a union and conducting strikes and mobilizations. However, before the clashes with the municipal administration, some got sick and others opted for individual forms of resistance. The union of municipal health servers, founded in 1988, turned from a combative stance to cooperation with the management in the 2000s. We conclude that, based on the difficulties described, it is up to the Cascavel public health sector workers the challenge to reflect on the past and continue trying to build collective strategies for organizing to defend their interests facing the management.

Keywords workers; worker's health; health staff; management of human resources in health. 


\section{Introdução}

O problema da organização coletiva dos trabalhadores na luta por seus direitos tem se revelado uma questão candente nas últimas décadas. Num cenário de profundas alterações no mundo do trabalho, com consequente crise do sindicalismo (Antunes, 1995; Santos, 2006) e precarização (Antunes, 2008), diversos estudos buscam compreender as limitações e possibilidades históricas das organizações fundadas pela classe trabalhadora no enfrentamento com o capital.

Entretanto, existem poucos estudos que tomam como objeto a organização coletiva dos trabalhadores no setor saúde. Aqueles conduzidos por pesquisadores que se inserem nesse campo e que se debruçam sobre a questão do 'trabalho em saúde' têm enfatizado dimensões da gestão, dos aspectos técnicos e organizacionais e das enfermidades relacionadas ao trabalho.

Adotando como referência o conceito proposto por Noriega (1993, p. 186, tradução nossa), em que a saúde é compreendida como "a capacidade que um grupo tem, na sociedade, para controlar e dirigir individual e coletivamente seus processos vitais, sua forma de viver", um estudo que pretende tomar como objeto a organização coletiva dos trabalhadores do setor saúde tem possibilidade de contribuir para a apreensão de uma dimensão importante de sua saúde, ao responder a questão: quais as estratégias, historicamente construídas, de resistência individual ou luta coletiva utilizadas pelos trabalhadores municipais de saúde e qual a reação do gestor público municipal frente à mobilização dos trabalhadores?

Este estudo foi desenvolvido com a finalidade de analisar a trajetória do movimento de trabalhadores dos serviços municipais de saúde de Cascavel, no Paraná, no enfrentamento de questões relacionadas ao trabalho, apreendendo-a como uma experiência singular de organização coletiva e, ao mesmo tempo, inserida no contexto mais geral de acumulação capitalista.

\section{Métodos}

Cascavel localiza-se na região Oeste do estado do Paraná. Com aproximadamente 300 mil habitantes, é considerado um polo universitário e um polo regional de prestação de serviços, principalmente de saúde. A economia da cidade está ligada ao agronegócio e às agroindústrias. Somente no setor de avicultura, um dos mais expressivos da região, mais de dois milhões de aves são abatidas diariamente (Cascavel, 2016).

Nesta pesquisa qualitativa os dados foram coletados por meio de entrevista semiestruturada com oito trabalhadores dos serviços municipais de saúde lideranças da organização coletiva dos servidores e aceitaram partici- 
par da pesquisa. As entrevistas foram feitas entre maio e agosto de 2014 e os sujeitos foram selecionados mediante o uso da técnica de bola-de-neve (snowball sampling) na qual o entrevistado inicial indica outros possíveis sujeitos da pesquisa e assim por diante (Atkinson e Flint, 2001).

Entre os entrevistados havia um indivíduo do sexo masculino e sete indivíduos do sexo feminino, trabalhadores de serviços de saúde vinculados à Secretaria Municipal de Saúde (SMS) ou ex-trabalhadores, de diversas categorias profissionais, entre elas enfermagem, serviço social, nutrição e psicologia.

O período histórico contemplado nas entrevistas foi compreendido entre os anos de 1976 e 2014. Definiu-se o ano inicial empiricamente a partir do trabalhador mais 'antigo' entrevistado, que começou suas atividades na SMS em 1976, e sua fala contempla o período neste ano. Além disso, o grupo de sujeitos entrevistados constituiu um 'mosaico', isto é, apesar de nenhum deles ter trabalhado na SMS durante todo o período contemplado na pesquisa (1976-2014), nenhum ano dentro do período analisado ficou 'descoberto'. De fato, suas falas contribuíram como partes de um todo. Optou-se por não divulgar o ano em que cada trabalhador iniciou e findou sua atuação na SMS, pois isso poderia comprometer seu anonimato.

Essa questão suscita a apresentação de algumas limitações do estudo. Em primeiro lugar, optou-se por utilizar apenas fontes orais, o que consiste em uma importante limitação. Quando se trabalha com fontes orais que envolvem a memória, deve-se atentar para “as fraquezas da própria memória, sua formidável capacidade de esquecer, que pode variar em função do tempo presente, suas deformações e seus equívocos, sua tendência para a lenda e o mito" (Joutard, 2000, p. 34). Contudo, a intenção desta pesquisa também é "dar voz àqueles que normalmente não a têm" (Joutard, 2000, p. 33), neste caso, os trabalhadores de saúde de um município no interior do Paraná. A fonte oral dá acesso a toda uma série de realidades que raramente aparecem nos documentos escritos. Ademais, é uma das 'bandeiras' do campo da saúde do trabalhador a defesa da incorporação do saber destes na produção de conhecimentos laborais e o processo saúde-doença, pressupondo que são os que possuem, de fato, tal conhecimento (Laurell e Noriega, 1989).

Em segundo lugar, há insuficiente produção teórica sobre aspectos sóciohistóricos do município que auxiliem na articulação entre os aspectos da conjuntura particular e os gerais, mais estudados e difundidos. Dessa forma, as análises limitam-se a abordar os problemas informados pelos sujeitos entrevistados, buscando vinculá-los ao contexto mais geral, compreendendo a relação existente entre os níveis singular, particular e geral da realidade, ainda que assumida a dificuldade em realizar tal concatenação na ausência de muitos aspectos não descritos ou analisados teoricamente. Assim, o estudo sugere a necessidade de futuras investigações sobre as particularidades de aspectos políticos, sociais e históricos deste município no intuito de aprofundar as análises aqui expostas. 
Após a transcrição, procedeu-se à leitura detalhada das entrevistas. Os procedimentos de análise dos dados seguiram as orientações de Minayo (2008).

Nos resultados e discussão, primeiro apresentam-se as percepções dos trabalhadores entrevistados sobre a realidade vivenciada nos serviços municipais de saúde. Na sequência, as estratégias adotadas pelo movimento dos trabalhadores no enfrentamento das questões identificadas como problemas a serem resolvidos. No terceiro momento, buscou-se traçar uma trajetória do sindicato dos servidores municipais como estratégia singular de organização coletiva. E, finalmente, a percepção dos trabalhadores a respeito da conduta dos gestores municipais frente às mobilizações. Na apresentação dos resultados, são descritos, inicialmente, os pontos comuns em todos os períodos históricos, para posteriormente se destacarem as singularidades de cada período.

O estudo seguiu as normas para pesquisas com seres humanos, dispostas pela resolução n. 466/12, do Conselho Nacional de Saúde (Brasil, 2013). Foi aprovado pelo Comitê de Ética em Pesquisa da Universidade Estadual do Oeste do Paraná (Unioeste), conforme o parecer n. 497.098 de 12/12/2013 (CAAE: 24005613.1.0000.0107). Todos os indivíduos aceitaram livremente participar da pesquisa mediante assinatura do termo de consentimento livre e esclarecido. Ademais, a identidade dos entrevistados foi preservada, utilizando-se a letra 'E' e o número sequencial da entrevista (E1, E2, E3 e assim por diante) para diferenciá-los.

\section{Resultados e discussão}

Nesta análise, o período histórico da pesquisa foi assim dividido: de 1976-1988, 1989-2000 e 2001-2014. O primeiro período (1976-1988) diz respeito aos mandatos dos prefeitos Pedro Muffato (MDB), empresário (até 1977); Jacy Scanagatta (PDS), empresário dos ramos agropecuário, automotivo e de comunicações (1977-1983), e Fidelcino Tolentino (PMDB), advogado (1983-1988). Além disso, o período é marcado no âmbito nacional pela fase final da ditadura militar e início da redemocratização.

O segundo período (1989-1999) se enquadra na chamada década do 'neoliberalismo' (Oliveira, 2003, p. 27) e marcado pelo primeiro e segundo mandatos de Salazar Barreiros (PP), advogado - entre 1989-1992 e 1997-2000 -, e pelo segundo mandato de Fidelcino Tolentino (PMDB), entre 1993-1996. Ademais, foi a década do processo de reabertura da democracia burguesa no Brasil.

O terceiro período (2001-2014) assinala dois mandatos (e o início do terceiro) de Edgar Bueno (PDT), empresário - entre 2001-2004, 2009-2012 e 2012-2014 -, e um mandato de Lisias Tomé (PSDC), médico e empresário, 
entre 2005-2008. Na conjuntura nacional, diz respeito ao final do governo Cardoso (até 2002), e aos governos Lula (2003-2010) e Dilma (2011-2014).

O terceiro mandato de Edgar Bueno, a partir de 2012, foi marcado pelos pedidos de afastamento e cassação, efetuados devido à suspeita de fraude eleitoral (Cruz, 2013). A situação seguiu sem definição nos anos subsequentes. As gestões de Fidelcino Tolentino e Salazar Barreiros também foram alvo de investigações por suspeita de irregularidades (Cruz, 2012).

Cumpre destacar que o prefeito Salazar Barreiros deixava em 1989 a presidência da Coopavel (Cooperativa Agropecuária Cascavel Ltda.) para se tornar prefeito. Na época, ele afirmou que seu governo esperava que o império da soja permanecesse no futuro (Corazza, 2015). A expectativa se concretizou. Outros prefeitos também têm origem e vinculam-se com o empresariado, isto é, os indivíduos a governar no período estudado acusam uma permanência dos interesses do setor empresarial no comando da cidade.

No setor saúde, durante o período analisado, a rede pública de atendimento à população ampliou-se consideravelmente, muito em função da municipalização do Sistema Único de Saúde (SUS) e a cidade se tornou polo regional na prestação de serviços de saúde. Além da construção de diversas Unidades Básicas de Saúde (UBS) e Unidades de Pronto Atendimento (UPA), houve a construção e ampliação do Hospital Universitário do Oeste do Paraná (HUOP) (Corazza, 2015) e um aumento marcadamente do setor privado de saúde.

Buscou-se compreender a experiência singular de organização coletiva dos trabalhadores da saúde inserida e concatenada a uma conjuntura geral de crise do capitalismo (Mendes, 2015), de acumulação flexível (Harvey, 2014), de políticas neoliberais (Campos, Viana e Soares, 2015) e de profundas alterações no mundo do trabalho (Antunes, 1995). Esse contexto, marcado por uma crise das formas tradicionais de organização da classe trabalhadora e, em especial, por uma nova crise do sindicalismo (Santos, 2006), será também observado nos relatos dos entrevistados.

\section{Os problemas identificados pelos trabalhadores municipais de saúde}

Os problemas do cotidiano laboral identificados pelos trabalhadores constituíram, em grande medida, a pauta de reivindicações de seu movimento em todo o período analisado (Quadro 1).

As questões salariais e de jornada de trabalho perpassaram o movimento no decorrer de todo o período estudado. No primeiro período (1976-1988), o salário possuía um componente fixo e outro variável, definido por produtividade. Os baixos salários levaram alguns a procurarem outros vínculos empregatícios na tentativa de aumentar a renda mensal. 
Quadro 1

\begin{tabular}{|c|c|c|c|c|}
\hline \multicolumn{5}{|c|}{ Realidade vivenciada pelos trabalhadores e reivindicações. Cascavel, Paraná, 1976-2014 } \\
\hline Período & & & Temas centrais & \\
\hline 1976-1988 & Salário & $\begin{array}{l}\text { Diminuição } \\
\text { da jornada }\end{array}$ & $\begin{array}{c}\text { Estrutura física e } \\
\text { força de trabalho precárias }\end{array}$ & Relação com a gestão \\
\hline $1989-2000$ & Salário & $\begin{array}{l}\text { Diminuição } \\
\text { da jornada }\end{array}$ & $\begin{array}{l}\text { Isonomia entre } \\
\text { profissionais }\end{array}$ & $\begin{array}{l}\text { Plano de Cargos, } \\
\text { Carreiras e Salários }\end{array}$ \\
\hline 2001-2014 & Salário & $\begin{array}{c}\text { Manutenção da } \\
\text { jornada conquistada }\end{array}$ & $\begin{array}{l}\text { Isonomia entre } \\
\text { profissionais }\end{array}$ & $\begin{array}{l}\text { Plano de Cargos, } \\
\text { Carreiras e Salários }\end{array}$ \\
\hline
\end{tabular}

Fonte: Os autores.

Na década de 1990, diante da pressão de algumas categorias profissionais pelo aumento do salário - tendo a categoria médica recebido um aumento salarial significativo -, a gestão sugeriu a redução da jornada de trabalho para trinta horas semanais (Cascavel, 1991), como forma de compensação. Os baixos salários permanecem relatados como problema enfrentado na década de 2000, mas perdem a centralidade na pauta de reivindicações.

A diminuição da jornada de trabalho, diretamente imbricada com a questão salarial, já era discutida desde a década de 1970. Essa condição, conquistada na década de 1990, foi alterada no início dos anos 2000, quando a gestão suspendeu a jornada de trinta horas semanais, e os trabalhadores retornaram à de quarenta horas semanais. Entre o final de 2004 e o início de 2005, os trabalhadores conseguem a aprovação na Câmara Municipal de Vereadores da 'Lei das trinta horas' (E6) e permanecem com jornada de trinta horas semanais até 2014, ainda que o gestor municipal havia tentado derrubá-la por meio de uma Ação Direta de Inconstitucionalidade (Adin).

O conflito entre capital e trabalho assume centralidade na sociedade capitalista, uma vez que "a história das sociedades até hoje existentes é a história da luta de classes" (Marx e Engels, 1998, p. 40). A limitação da jornada de trabalho e a remuneração da força de trabalho têm ocupado, historicamente, um lugar central nas lutas dos movimentos de trabalhadores. Sua importância para o conflito capital-trabalho é explicada pela teoria marxiana do mais-valor: uma jornada de trabalho mais extensa contém maior tempo de trabalho excedente, ou seja, maior valor apropriado pelo capitalista; uma jornada reduzida, em contrapartida, representa maior possibilidade da apropriação de uma menor taxa de mais-valor pelo capitalista, uma vez que o tempo de trabalho necessário 3 ocupa a maior parte da jornada. Algo semelhante ocorre com o salário: um salário maior representa um tempo maior de trabalho necessário, uma menor apropriação de mais-valor pelo capitalista e a 
possibilidade da força de trabalho se reproduzir em melhores condições (Marx, 2013).

De acordo com Alves (2009), sob o neoliberalismo, a delimitação da jornada de trabalho tornou-se um campo de luta importante no Brasil. A extensão do tempo laboral consumindo o tempo de vida pessoal e familiar tornou-se uma das preocupações dos assalariados. Na medida em que tempo de vida se inverte em tempo de trabalho, ocorre a perda de espaços de sociabilidade humano-social, avassala-se o tempo de vida social, uma vez que o tempo de trabalho colonizou o tempo de vida. Nesse sentido, é compreensível a preocupação com a delimitação da jornada de trabalho.

No primeiro período (1976-1988), os problemas relacionados à estrutura física precária das UBSs e à falta de trabalhadores também se destacaram. Tal fato é perceptível na fala de um dos entrevistados: "Nas unidades básicas, a estrutura física era bem precária e em termos de recursos humanos também" (E2). Na década de 1990, a estrutura física e o quadro de profissionais deixam de ser citados pelos trabalhadores como um problema enfrentado. Isso se deve, possivelmente, à alteração na dinâmica da organização dos serviços de saúde, proporcionada pela implantação do SUS pela Constituição Federal de 1988, com consequente descentralização e municipalização dos serviços.

Nesse primeiro período, a relação dos trabalhadores com uma gestão autoritária e centralizadora das decisões foi relatada como problema central vivenciado. Não havia mecanismo formal de negociação em que os trabalhadores se sentissem seguros e amparados para lutar por suas reivindicações. Portanto, "não tinha espaço pra se discutir" (E2) com a gestão.

A questão salarial, conjugada a outras (como a jornada de trabalho), foi contextualizada, em todo o período estudado, vinculada à falta de isonomia entre as categorias profissionais, mais especificamente, a desigualdade no tratamento à categoria médica em relação às outras. Esta relação desigual entre categorias profissionais e gestão tornou-se um dos principais problemas vivenciados pelos trabalhadores na década de 2000, gerando frequentes mobilizações, angústia e constrangimentos para eles: “Hoje ser servidor é amargar angústias de ver o teu colega, que não é mais importante do que tu no contexto, tendo um crescimento econômico à custa do que deveria estar sendo direcionado pro teu salário" (E8).

A luta pelo Plano de Cargos, Carreiras e Salários (PCCS) emergiu em meados dos anos 1990, após a implantação do SUS, com a finalidade de aglutinar as reivindicações citadas anteriormente: a questão salarial, a jornada de trabalho e a isonomia entre as categorias profissionais. O município possuía um PCCS para os servidores, mas o plano não atendia as necessidades e direitos dos trabalhadores da saúde (E4) e estava desatualizado (E7).

Somente em 2004 a gestão municipal inicia um processo de reformulação do PCCS - que culmina com a confecção de um plano (Cascavel, 2004) -, sem 
a participação direta dos trabalhadores, de modo autoritário e centralizador da gestão municipal, conforme aponta E8:

A gente [...] foi informada que iria sair um PCCS e, junto com essa informação, foi esclarecido que ninguém ia ter acesso à discussão, que um grupo altamente restrito é que iria definir esse plano. O que é que estava previsto nisso? A questão da carga horária, questões salariais, tudo. Como é que foi feito o plano? Ele foi feito de forma exclusa, a portas fechadas.

No setor saúde, desde a institucionalização do SUS, o PCCS foi uma exigência para a transferência de recursos financeiros fundo a fundo entre as esferas de governo, determinada pela lei federal n. 8.142/1990 (Brasil, 1990) e ainda é um problema nos municípios brasileiros, alvo de preocupação da Secretaria de Gestão do Trabalho e da Educação em Saúde (SGTES) do Ministério da Saúde, demonstrada pela publicação das Diretrizes Nacionais para a Elaboração dos PCCS no SUS (Brasil, 2006).

Com base na análise da construção da pauta de reivindicações dos trabalhadores da saúde no período, pode-se inferir que em cada período histórico, além de emergirem novos problemas, reaparecem os velhos insuficientemente resolvidos, como o caso da jornada de trabalho, por exemplo, presente nos anos 1990 como uma reivindicação e na década de 2000 como a defesa de uma conquista a ser mantida.

\section{Estratégias de organização e ação coletiva}

Mediante a identificação das situações-problema apresentadas anteriormente, os trabalhadores procuraram estratégias de organização para intervir sobre elas, buscando solucioná-las. Conforme o Quadro 2, a estratégia de reunir os trabalhadores para discutir os problemas vivenciados perpassa todo o período analisado e é o ponto de partida para a definição de outras ações. Já em meados da década de 1980, realizavam-se encontros semanais para refletir a respeito dos problemas: "Em determinado momento, [...] começou a aparecer toda a problemática que era vivenciada nas unidades de saúde" (E1). Inicialmente, eles também tinham um caráter de formação política, com participação de representantes de partidos políticos e pouca participação dos trabalhadores. 
Quadro 2

\begin{tabular}{|c|c|c|c|c|}
\hline \multicolumn{5}{|c|}{ Estratégias de luta adotadas pelos trabalhadores. Cascavel, Paraná, 1976-2014 } \\
\hline \multirow{2}{*}{$\begin{array}{c}\text { Período } \\
1976-1988\end{array}$} & \multicolumn{4}{|c|}{ Temas centrais } \\
\hline & $\begin{array}{l}\text { Reuniões entre } \\
\text { trabalhadores }\end{array}$ & Organização sindical & Greves & $\begin{array}{l}\text { Reuniões com } \\
\text { a gestão }\end{array}$ \\
\hline $1989-2000$ & $\begin{array}{l}\text { Reuniões entre } \\
\text { trabalhadores }\end{array}$ & $\begin{array}{l}\text { Criação de um } \\
\text { 'sindicato próprio } \\
\text { da saúde' }\end{array}$ & $\begin{array}{l}\text { Associação dos } \\
\text { assistentes sociais }\end{array}$ & - \\
\hline 2001-2014 & $\begin{array}{l}\text { Reuniões entre } \\
\text { trabalhadores }\end{array}$ & $\begin{array}{l}\text { Criação de um } \\
\text { 'sindicato próprio } \\
\text { da saúde' }\end{array}$ & $\begin{array}{l}\text { Associação dos } \\
\text { assistentes sociais }\end{array}$ & $\begin{array}{l}\text { Reuniões com a gestão } \\
\text { para discutir o Plano de } \\
\text { Cargos, Carreiras e Salários }\end{array}$ \\
\hline
\end{tabular}

Fonte: Os autores.

Uma questão importante colocada pelos trabalhadores era a autonomia do movimento em relação à gestão: "A gente evitou chamar os gestores para as reuniões" (El). Um dos entrevistados utilizou o termo 'clandestino' (E1) para qualificar a natureza dos encontros. Em finais da década de 1980, decidiu-se pela abertura dessas reuniões para todos os trabalhadores da SMS, com ampla divulgação. O objetivo era, claramente, a discussão da realidade do trabalho desenvolvido nos serviços de saúde e a definição de ações para seu enfrentamento como, por exemplo, a formação de comissão para negociar com o gestor.

Porém, as consequências da primeira reunião de negociação com a gestão foram 'traumáticas' para o conjunto de trabalhadores, especialmente para aqueles que lideravam efetivamente o movimento, uma vez que eles sofreram um processo administrativo e ficaram afastados do trabalho. Essa questão é discutida com maior profundidade posteriormente, na seção que apresenta as reações dos gestores frente às mobilizações de trabalhadores. Não obtendo êxito com a estratégia da 'reunião com a gestão' e amparados pela nova Constituição promulgada em 1988, os trabalhadores da saúde e os da prefeitura municipal (da educação, transporte, obras etc.) decidiram pela criação de um sindicato dos servidores municipais, cuja assembleia de fundação foi realizada ainda no ano de 1988. A perspectiva democrática permeava as ações do sindicato, tanto que "a composição da diretoria (...) contemplava trabalhadores dos vários setores da prefeitura" (El).

A coalizão do sindicato com os trabalhadores e sua credibilidade perante eles era tamanha que, ainda em finais da década de 1980, foi possível a organização de uma greve dos servidores municipais, mobilizando todos os setores da prefeitura, com reivindicações fundamentalmente salariais. Na avaliação do entrevistado El, o principal ganho da greve - que não obteve êxito nas suas reivindicações salariais - foi aprimorar a formação política e a consciência de classe dos trabalhadores envolvidos no movimento. 
Em meados da década de 1990, aqueles vinculados à secretaria de educação criaram seu próprio sindicato, desmembrando-se do dos servidores municipais. A criação desse sindicato repercutiu no movimento dos trabalhadores da saúde, que intentaram criar também o seu próprio, pois avaliaram que o de servidores municipais deixou de representá-los frente à gestão. Essa intenção atravessa toda a década de 2000. No entanto, questionava-se se a criação de outro sindicato seria a melhor alternativa para o movimento:

A gente se questiona se a saída é essa, criar um sindicato, ou fortalecer o sindicato que existe. (...) Acho que o sindicato da saúde não seria uma boa alternativa. Teríamos que participar e reorganizar esse sindicato que existe. Porque criar mais um sindicato, acho que desmobiliza e desarticula, nos enfraquece mais ainda (E6).

No final da década de 1990 foi criada a "associação dos assistentes sociais" (E3), com reuniões mensais para estudo e discussão da realidade de trabalho vivenciada por estes profissionais empregados tanto no setor público quanto no privado. A atuação da associação se pautava pela participação nos conselhos e conferências municipais de saúde e permaneceu atuante durante a década de 2000, inclusive sendo transformada em núcleo regional de serviço social, abarcando não só trabalhadores de Cascavel, mas de toda a região Oeste do Paraná. Contudo, por volta de 2012, suas atividades foram suspensas, devido ao "esvaziamento" (E6) desse espaço.

Quando, em 2004, o então prefeito Edgar Bueno anunciou a elaboração de um novo PCCS, sem a participação dos trabalhadores, o coletivo começou a pressionar a gestão para a abertura das discussões. A gestão "sentiu o problema", isto é, percebeu que o movimento ganhava força e se tornava uma ameaça, e abriu as discussões em grupo com o objetivo de "ganhar tempo e esfriar o movimento" (E7), segundo a percepção dos trabalhadores.

Mas foi a partir desses debates que os trabalhadores da saúde conseguiram reaver seu direito à jornada de trinta horas semanais, por meio da "Lei das trinta horas" (E8), aprovada na Câmara Municipal de vereadores em 2005, na gestão de Lisias Tomé. Com a entrada de um médico (Lisias) no comando da prefeitura, os trabalhadores tinham a esperança de que as condições de trabalho no setor saúde pudessem melhorar. Segundo eles, não foi o que aconteceu.

Por volta de 2012, com a contratação de novos trabalhadores, buscou-se retomar as reuniões para a discussão dos problemas vivenciados no trabalho. Entretanto, os entrevistados identificaram a inexperiência política e o desconhecimento do contexto do local de trabalho dos novos trabalhadores ao convidarem para as reuniões indivíduos que se alinhavam politicamente à 
gestão, "informantes, dedos-duros" (E7). Era a primeira tentativa de organização coletiva desde 2006: "Só agora a gente foi tentar e foi uma ou duas reuniões e o negócio acabou" (E7).

\section{A atuação do sindicato dos servidores municipais}

O sindicato foi criado ao final de 1988, a partir das atividades de um grupo de trabalhadores vinculados a todos os setores da prefeitura municipal, que pretendia legitimar coletivamente suas lutas perante a gestão e difundir a discussão a respeito do trabalho vivenciado nos serviços públicos. Desde a sua fundação até o ano de 1994, o sindicato realizou pelo menos dois grandes movimentos grevistas, cujos objetivos eram melhoria e atualização no pagamento de salários atrasados; melhores condições de trabalho e da qualidade da assistência à população; e ampliação da estrutura física das unidades e do quadro de trabalhadores. Agia-se na perspectiva da negociação: "Se caso ela não chegasse a termo, aí a gente tinha o direito de greve" (E1). Havia, na época, uma articulação do sindicato municipal com outros deste município e de outras cidades paranaenses, que, com membros mais experientes, apoiavam o sindicato em formação.

Todavia, grande parte dos trabalhadores envolvidos na construção do sindicato acabou rompendo seu vínculo com a prefeitura municipal, quando encontraram propostas melhores de emprego e pelo desgaste do embate frequente com a gestão. Pari passu, de acordo com os entrevistados, o sindicato foi perdendo sua postura combativa e cada vez mais a de cooperação com a gestão. A falta dos trabalhadores mais antigos e combativos pode ter contribuído para a aceleração do processo de crise sindical.

A partir de meados de 1990, os entrevistados passam a relatar uma desconfiança no sindicato. Afirmam, por exemplo, que ele "é comprado" (E4), ou que foi "vendido" (E7) pelos que dele participavam ativamente em troca de cargos de chefia e "poder" (E7). De acordo com um dos entrevistados, "o sindicato às vezes tem uma postura, uma atuação muito contraditória, parece que é meio esquizofrênico, não define, exatamente, de que lado está" (E6). Essa tendência de cooperação com a gestão se mantém durante a década de 2000, se agravando, porém, em meados da década, quando, segundo relatos, parece abandonar quase totalmente a defesa dos interesses do trabalhador em virtude de uma aparente 'aliança' com os gestores.

A percepção dos trabalhadores é a de que, a partir de 2010, o sindicato "não faz nada, só coloca panos quentes, coloca ali pra esconder, fazer de conta" (E7). Sua atuação parece ser no sentido de legitimar as ações propostas pela gestão e de "boicotar" (E8) a ação dos demais trabalhadores, organizados de forma autônoma, se esta vai contra os interesses daquelas. 
A alteração do posicionamento do sindicato perante os trabalhadores e a gestão se dá mediante um processo gradativo, no qual o sindicato vai progressivamente perdendo seu cariz combativo e assumindo uma postura de cooperação com a gestão. Aqui, outros materiais e fontes de dados (documentos, editais, atas, notícias de jornais etc.) poderiam auxiliar na verificação desse movimento percebido empiricamente pelos trabalhadores entrevistados, o que se sugere seja realizado em futuros estudos.

Alves (2000) defende a ideia de que o Brasil viveu, de 1978 a 1998, uma ascensão e crise do sindicalismo como movimento social e político. Para Antunes (2002), o sindicalismo brasileiro viveu na década de 1980 um momento particularmente positivo. Entre outros avanços, "houve aumento nos níveis de sindicalização" (Antunes, 2002, p. 80).

Entretanto, nos anos 1990 viria a grande sincronia histórica da ordem capitalista no Brasil com o que ocorria mundo afora, uma vez que o país se inseriria de modo dependente e subalterno na mundialização do capital sob o signo de políticas neoliberais. É no novo tempo da era neoliberal que se instaura, a partir dos anos 1990, uma crise do sindicalismo, visto que o mundo do trabalho estruturado, base do sindicalismo de classe organizado no país, é alvo de uma ofensiva do capital (Alves, 2000).

A trajetória do sindicalismo brasileiro dos anos 1980 e 1990 é de uma passagem da confrontação para a 'participação', que, para Ramalho (2003), se define pela participação do sindicato em quase tudo...

(...) desde que não se questione o mercado, a legitimidade do lucro, o que e para quem se produz, a lógica da produtividade, a sacra propriedade privada, enfim, os elementos básicos do complexo movimento do capital (Ramalho, 2003, p. 130-131).

Confrontando os dados colhidos a respeito da atuação do sindicato com o referencial teórico construído sobre a nova crise do sindicalismo brasileiro, pode-se inferir que o sindicato dos trabalhadores vinculados à prefeitura é, a um tempo, sujeito de um processo singular de experiência sindical e objeto de alterações estruturais que impactam nas formas de ser do movimento como um todo. Ou seja: a experiência aqui retratada compõe o movimento sindical brasileiro (e suas transformações ao longo das últimas décadas) ao mesmo tempo em que é expressão desse mesmo movimento e de suas transformações.

Devido à atuação do sindicato, os trabalhadores procuraram outras formas de organização, como as associações profissionais. Buscaram participar do processo eleitoral para disputar a direção do sindicato, contudo, os trabalhadores da saúde não conseguiram encontrar uma alternativa que superasse a crise, nem dentro e nem fora dele. 


\section{Percepção dos trabalhadores em relação às respostas dadas pela gestão}

A análise da reação dos gestores às mobilizações realizadas pelos trabalhadores (Quadro 3) pode contribuir para o desenvolvimento da ideia, já apresentada anteriormente, de que a gestão (tanto da prefeitura quanto da SMS), no decorrer do período estudado, se manteve 'autoritária', 'pouco democrática' e centralizadora das decisões.

No período entre 1976 e 1988, a reação dos gestores às mobilizações foi explicitamente autoritária. Descoberta a reunião 'clandestina' realizada em meados de 1987, citada anteriormente, a comissão eleita reuniu-se com o prefeito. Inicialmente, ele teria dito que "ia pensar" (El) numa forma de atender os trabalhadores. No entanto, aqueles que compunham a comissão passaram a responder um processo administrativo, ficando aproximadamente quarenta dias afastados do trabalho.

O discurso da gestão era de que "provavelmente tinha uma maçã podre lá [entre os trabalhadores], e que essa maçã podre que acabou contaminando [os demais]" (El). O 'interlocutor' do movimento com a gestão e que dera visibilidade ao movimento foi demitido. Ele "entrou na justiça" (El), questionando a decisão, e obteve o direito de ser reintegrado, mas preferiu não o ser, mediante indenização.

Quadro 3

\begin{tabular}{|c|c|c|c|c|c|}
\hline Perlodo & & & Temas centrais & & \\
\hline 1976-1988 & $\begin{array}{c}\text { Mover processo } \\
\text { administrativo contra } \\
\text { os trabalhadores }\end{array}$ & $\begin{array}{c}\text { Demitir ou 'cooptar' } \\
\text { trabalhadores } \\
\text { combativos }\end{array}$ & $\begin{array}{l}\text { ‘Cortar' os adicionais } \\
\text { recebidos pelos } \\
\text { trabalhadores mobilizados }\end{array}$ & $\begin{array}{l}\text { Inviabilizar o } \\
\text { trabalho }\end{array}$ & $\begin{array}{l}\text { Elaborar 'dossiê' } \\
\text { sobre os } \\
\text { trabalhadores }\end{array}$ \\
\hline $1989-2000$ & $\begin{array}{l}\text { Transferir de forma } \\
\text { compulsória os } \\
\text { trabalhadores de } \\
\text { local de trabalho }\end{array}$ & $\begin{array}{l}\text { 'Cooptar' os } \\
\text { trabalhadores } \\
\text { combativos }\end{array}$ & $\begin{array}{l}\text { Inserir'infiltrados' no } \\
\text { movimento de } \\
\text { trabalhadores }\end{array}$ & - & - \\
\hline 2001-2014 & $\begin{array}{l}\text { Desmobilizar } \\
\text { reuniões }\end{array}$ & $\begin{array}{c}\text { Adin contra a lei das } \\
30 \text { horas }\end{array}$ & $\begin{array}{l}\text { Indiferença frente às } \\
\text { reivindicações }\end{array}$ & $\begin{array}{c}\text { Buscar 'esfriar o } \\
\text { movimento' }\end{array}$ & $\begin{array}{l}\text { Rejeitar o diálogo } \\
\text { com os trabalhadores } \\
\text { organizados fora } \\
\text { do sindicato }\end{array}$ \\
\hline
\end{tabular}

Fonte: Os autores. 
Após a criação do sindicato, a gestão passou a adotar uma série de estratégias para desestabilizá-lo. Ainda nas primeiras semanas de fundação, “o pessoal [da prefeitura] passava nas Unidades de Saúde dizendo pro pessoal não se filiar ao sindicato" (E1). Uma das trabalhadoras, liberada do trabalho para fazer parte da direção do sindicato, teve seu adicional de produtividade cortado e relatou que, com o salário pela metade, não conseguiu permanecer na entidade.

Os trabalhadores sofreram, ainda, "tentativas de cooptação" (E1) pela gestão. Isto é, tentava-se "comprar" (E1) a lealdade deles mediante algum benefício individual, além de inviabilizar o trabalho daqueles que assumiam uma postura mais combativa, com o objetivo de tornar a situação insuportável. Outra ação praticada pela gestão era o envio de um "dossiê" (E5) dos considerados "agitadores" (E5) para os empregos que os mesmos iriam assumir após deixar a SMS.

A postura da gestão permaneceu semelhante na década de 1990. Além das cooptações, "às vezes oferecem a coordenação de um programa ou de um serviço, de uma unidade", ou até "oferecem um cargo" (E6). Nessa década, ela passou a adotar a estratégia de transferir (ou ameaçar transferir) compulsoriamente os trabalhadores do local de trabalho, como forma de reprimir o movimento e de impedir a formação de um vínculo entre a equipe de trabalho: "Quando você começava a se estruturar na unidade, eles te mandavam pra outro lugar" (E2). Os assistentes sociais que participam de alguma mobilização, por exemplo, são constantemente ameaçados de serem transferidos da SMS para a Secretaria de Ação Social (SAS).

Além disso, nas reuniões realizadas pelos trabalhadores, "ia uma funcionária dos recursos humanos pra anotar o nome de quem estava" (E7), um "infiltrado" (E7) para dedurar os colegas que participavam dos movimentos.

Entre 2001 e 2014, frente às tentativas dos trabalhadores de negociar com os gestores, a estratégia adotada pelos últimos é a de desmarcar e remarcar reuniões "ad aeternum: eles nunca conseguiram falar com o prefeito, ele marcava um dia e daí desmarcava (...) remarcava e acabou por aí" (E7).

Em tempos de cooperação com o sindicato dos servidores municipais, a gestão adotava a estratégia de rejeitar o diálogo com trabalhadores organizados fora dele, alegando só dialogar com representantes da organização sindical: "Quando eu comecei a levantar as polêmicas, a coordenadora da reunião olhou pro cara do sindicato e disse: 'Olha, de agora em diante eu só admito pronunciamento do (...) sindicato"' (E8).

Além disso, a gestão municipal buscava "esfriar o movimento" (E7). Quando se estava discutindo a atualização do PCCS, em 2004 (Cascavel, 2004), a gestão se antecipou e convocou as reuniões, antes que os trabalhadores se mobilizassem. Inicialmente, acreditou-se que a SMS iria atuar democraticamente. No entanto, posteriormente, a percepção dos tra- 
balhadores foi a de que o objetivo era meramente o de "ganhar tempo" (E7) nas disputas travadas.

Após a aprovação do PCCS e da 'Lei das 30 horas', o gestor municipal enviou ao Tribunal de Justiça uma Adin alegando uma emenda inserida por um dos vereadores aliados do prefeito. "Foi uma jogada muito da sórdida" (E8).

De modo geral, a gestão tende a justificar a recusa em atender às reivindicações pela falta de recursos financeiros: “O motivo que a administração justifica pra não nos atender é a questão do orçamento, do índice prudencial, da folha de pagamento" (E6). Entretanto, a prioridade dos gastos com força de trabalho tem sido os altos salários para os trabalhadores que assumem 'cargos de confiança'.

Na percepção dos trabalhadores, a postura da gestão foi de "indiferença" (E8) perante a situação vivenciada por eles e, de modo geral, pela situação dos serviços de saúde do município. Em todas as entrevistas, independente dos períodos abordados, a palavra 'autoritária' foi a mais utilizada para qualificar a gestão: "Não se tem muito diálogo, não se tem negociação. As decisões são feitas de cima pra baixo" (E6). Refletindo sobre a década de 2000, um entrevistado refere que quase sofreu um "colapso" (E8) por causa do enfrentamento com a gestão. Segundo o relato, os trabalhadores sofreram sucessivas 'pauladas' no decorrer de sua história de luta:

O processo histórico eu posso te dizer que teve, de lá até agora, um padrão de pauladas e pauladas... sai gestão e entra gestão, volta gestão (...) e parece que é sempre a mesma. Chega num ponto em que o povo cansa. Cansa muito com tudo isso aí (E8).

O desgaste e o sofrimento decorrentes do enfrentamento constante com a gestão foram referidos como elementos importantes da dinâmica recente de suas lutas. Muitos deles têm procurado se afastar do embate mais direto com a gestão para preservar a saúde. Alguns "precisaram de tratamento psicológico" (E3). Os trabalhadores "têm realmente percebido o adoecimento, muito adoecimento" e ouvem "dos colegas que os planos, o sonho de vida deles, é de se aposentar ou se exonerar" (E8).

Essa perspectiva tem levado parte dos trabalhadores que integram o movimento a deixar de participar das mobilizações, isolando-se e enfrentando a realidade individualmente.

Assunção (2011) apresenta uma revisão envolvendo diversos estudos que relatam as precárias condições de trabalho e de saúde dos trabalhadores do setor. Nele, ninguém tem escapado: todos estão expostos a agravos à saúde, especialmente o mental. A própria construção de uma política pública de saúde do trabalhador segue como desafio (Costa et al., 2013) que deve ser incorporado na agenda dos movimentos de trabalhadores, em especial daqueles vinculados ao setor saúde. 
A justificativa da gestão municipal de Cascavel em não atender as reivindicações dos trabalhadores devido aos limites em relação ao orçamento está ancorada na Lei de Responsabilidade Fiscal (LRF). Essa lei, sancionada em 2000, define que as despesas com força de trabalho não podem ultrapassar $60 \%$ da receita corrente líquida de estados e municípios e 50\% da União (Brasil, 2000). Ela seria uma consequência da reforma administrativa do Estado brasileiro, produto da ofensiva neoliberal no país (Koster, 2008; Martins e Molinaro, 2013). Em virtude de a saúde ser, assim como a educação, extremamente dependente de força de trabalho para o desenvolvimento das ações, a LRF tem se tornado uma grande dificuldade enfrentada pelos setores que executam as políticas sociais.

A despeito do limite para o gasto com força de trabalho na esfera municipal, estipulado pela LRF - que tem estimulado o gestor municipal a, além de lançar mão de formas de contrato precárias (Silva e Silva, 2007), pressionar para baixo o salário dos trabalhadores -, a gestão pública do município de Cascavel tem priorizado os gastos com a remuneração dos altos salários dos 'cargos de confiança' e 'assessores'.

Ademais, a forma de gestão adotada pela SMS é condizente com aquela que trata os trabalhadores como meros 'recursos', cujas origens remontam a 'administração científica', proposta por Taylor e Ford (Garcia, 2010), e que tenta subsumir o trabalho vivo ao trabalho morto, buscando aproximar o ser humano ao funcionamento de uma máquina (Campos, 2010). Isso ocorre apesar dos esforços do Ministério da Saúde, por meio, principalmente, da instituição da SGTES, em 2003, em estimular a adoção de gestões mais democráticas, que contemplem trabalhadores e usuários nos processos decisórios (Brasil, 2009).

Concorda-se com Bedin et al. (2014) que exercer a gestão dos serviços de saúde é uma tarefa complexa. Nesse sentido, na gestão em saúde, mostram-se necessárias

práticas dialógicas que busquem a concretização de acordos e compromissos mantenedores dos princípios do SUS, que vislumbram relações democráticas e participativas na construção de práticas voltadas para o cuidado integral no campo da saúde (Bedin et al., 2014, p. 1.399).

Diante da complexa situação em que se encontra o trabalho nos serviços públicos de saúde de Cascavel, os trabalhadores mostram-se incrédulos quanto à possibilidade de alteração do cenário, isolando-se em suas unidades a fim de evitar as angústias e os conflitos e preservar sua saúde. Essas formas de resistência, mesmo que individuais, podem contribuir para a manutenção do emprego e para evitar a transformação do sofrimento em adoecimento (Brant e Minayo-Gomez, 2009). 


\section{Conclusões}

Na trajetória do movimento de trabalhadores da SMS de Cascavel no enfrentamento de questões relacionadas ao trabalho e à gestão do trabalho, identificou-se que eles procuraram encontrar estratégias de mobilização e organização coletiva desde reuniões sistemáticas até greves e mobilizações, organizadas pelo sindicato constituído no período analisado. A gestão, em contrapartida, em um contexto geral favorável à desmobilização dos trabalhadores, buscou estratégias que produzissem o desmonte das organizações coletivas por eles fundadas. Desgastada psicologicamente, uma parte deles optou por se afastar do processo de enfrentamento com a gestão, contando os dias para a chegada da aposentadoria ou esperando trocar de emprego.

A organização sindical, fundada em finais da década de 1980, na percepção dos entrevistados, seguiu a tendência geral de crise do sindicalismo. Deixou de lado as estratégias combativas para assumir uma postura de cooperação com a gestão. Os trabalhadores, por sua vez, não conseguiram encontrar uma alternativa ao movimento sindical nem dentro e nem fora dele.

Com base nesse cenário, espera-se que as reflexões deste estudo possam contribuir para o grande desafio da classe trabalhadora, em geral, e, dos trabalhadores dos serviços municipais de saúde de Cascavel, em particular, que consiste na construção de uma organização coletiva que represente efetivamente os interesses da classe frente ao patronato. Para tanto, deve procurar estratégias de enfrentamento radicais, ou seja, tomar os problemas pela raiz (Marx, 2010) e caminhar em direção à emancipação social ou, no mínimo, dentro dos marcos do modo de produção capitalista, a uma realidade de trabalho o menos degradante possível.

\section{Colaboradores}

Leonardo Dresch Eberhardt e Manoela de Carvalho contribuíram igualmente em todas as etapas da elaboração do artigo. 
Resumen El tema de organización colectiva es una dimensión importante imbricada en la gestión del trabajo en salud y en la salud del trabajador. Este artículo analiza la trayectoria del movimiento de trabajadores de los servicios municipales de salud de Cascavel, ciudad del estado del Paraná, Brasil, en el enfrentamiento de cuestiones relacionadas al trabajo y a la gestión del trabajo. Fue utilizada la metodología cualitativa, con la realización de entrevista semiestructuradas y técnica de bola-de-nieve para la definición de amuestra. Los resultados indican que los trabajadores se organizan colectivamente, en el periodo analizado, por medio de reuniones periódicas, de la fundación de un sindicato y de la realización de huelgas y movilizaciones. Sin embargo, delante de los embates con la gestión municipal, algunos se enfermaron y otros optaron por formas individuales de resistencia. El sindicato de los servidores municipales de la salud, fundado en 1988, se fue de una actuación combativa para la cooperación con la gestión en la década de 2000. Fue concluido que, basados en las dificultades descritas, cabe a los trabajadores del sector público de salud de Cascavel el desafío de reflejaren sobre el pasado y continuaren buscando construir estrategias colectivas de organización que defiendan sus intereses frente a la gestión.

Palabras clave trabajadores; salud del trabajador; personal de salud; administración de recursos humanos en salud.

\section{Notas}

1 Fundação Oswaldo Cruz, Escola Nacional de Saúde Pública Sergio Arouca, Rio de Janeiro, RJ, Brasil.

$<$ leonardodeberhardt@gmail.com>

Correspondência: Fundação Oswaldo Cruz, Escola Nacional de Saúde Pública Sergio Arouca, Rua Leopoldo Bulhões, 1.480, Manguinhos, CEP 21041-210, Rio de Janeiro, RJ, Brasil.

2 Universidade Estadual do Oeste do Paraná, Cascavel, Paraná, Brasil.

$<$ manoela@hotmail.com>

3 Segundo Marx (2013), a jornada de trabalho é dividida entre trabalho necessário parcela em que o trabalhador produz o equivalente ao seu salário - e trabalho excedente - na qual o trabalhador produz um valor a mais, ou seja, o mais-valor que será apropriado pelo capitalista. 


\section{Referências}

ALVES, Giovanni. Do 'novo sindicalismo' à 'concertação social': ascensão (e crise) do sindicalismo no Brasil (1978-1998). Revista de Sociologia Politica, Curitiba, v. 15, p. 111$-124,2000$

ALVES, Giovanni. Trabalho e reestruturação produtiva no Brasil neoliberal - precarização do trabalho e redundância salarial. Revista Katálysis, Florianópolis, v. 12, n. 2, p. 188-197, jul./dez. 2009.

ANTUNES, Ricardo. Adeus ao trabalho?: Ensaio sobre a metamorfose e a centralidade do mundo do trabalho. São Paulo: Cortez, 1995.

ANTUNES, Ricardo. Trabalho, reestruturação produtiva e algumas repercussões no sindicalismo brasileiro. In: ANTUNES, Ricardo (org.). Neoliberalismo, trabalho e sindicatos: reestruturação produtiva no Brasil e na Inglaterra. São Paulo: Boitempo, 2002. p. 71-84.

ANTUNES, Ricardo. As formas de padecimento do trabalho. Saúde e Sociedade, São Paulo, v. 17, n. 4, p. 7-10, 2008.

ASSUNÇÃO, Ada A. Condições de trabalho e saúde dos trabalhadores da saúde. In: MINAYO-GOMEZ, Carlos; MACHADO, Jorge M. H.; PENA, Paulo G. L. (orgs.). Saúde do trabalhador na sociedade brasileira contemporânea. Rio de Janeiro: Editora Fiocruz, 2011. p. 453-478.

ATKINSON, Rowland; FLINT, John. Accessing hidden and hard-to-reach populations: snowball research strategies. Social Research Update, Guildford, n. 33, p. 1-4, 2001.

BEDIN, Dulce M. et al. Reflexões acerca da gestão em saúde em um município do sul do Brasil. Saúde e Sociedade, São Paulo, v. 23, n. 4, p. 1.397-1.407, 2014.

BRANT, Luiz C.; MINAYO-GOMEZ, Carlos. Manifestação do sofrimento e resistência ao adoecimento na gestão do trabalho. Saúde e
Sociedade, São Paulo, v. 18, n. 2, p. 237-247, 2009.

BRASIL. Lei n. 8.142, de 28 de dezembro de 1990. Dispõe sobre a participação da comunidade na gestão do Sistema Único de Saúde (SUS) e sobre as transferências intergovernamentais de recursos financeiros na área da saúde e dá outras providências. Diário Oficial [da] República Federativa do Brasil, Brasília, DF, 31 dez. 1990. Disponível em: <www.planalto.gov.br/ccivil_03/leis/ 18142.htm>. Acesso em: 27 jul. 2016.

BRASIL. Lei Complementar n. 101, de 4 de maio de 2000. Estabelece normas de finanças públicas voltadas para a responsabilidade na gestão fiscal e dá outras providências. Diário Oficial [da] República Federativa do Brasil, Brasília, DF, 5 maio 2000. Disponível em: <www.planalto.gov.br/ccivil_03/leis/ lcp/lcp101.htm>. Acesso em: 27 jul. 2016.

BRASIL. Ministério da Saúde. PCCS-SUS: diretrizes nacionais para a instituição de planos de carreira, cargos e salários no âmbito do Sistema Único de Saúde. Brasília: Ministério da Saúde, 2006. Disponível em: $<$ http://bvsms.saude.gov.br/bvs/publicacoes/ pccs_diretrizes_nacionais_planos_carreiras_ sus.pdf>. Acesso em: 25 jul. 2016.

BRASIL. Ministério da Saúde. Gestão do trabalho e da regulação profissional em saúde. 3. ed. Brasília: Ministério da Saúde, 2009. Disponível em: <http://bvsms.saude.gov.br/ bvs/publicacoes/agenda_positiva.pdf $>$. Acesso em: 25 jul. 2016.

BRASIL. Resolução n. 466 de 12 de dezembro de 2012. Diário Oficial [da] República Federativa do Brasil, Brasília, DF, 13 jun. 2013. Disponível em: <http://sintse.tse.jus.br/documentos/ 2013/Jun/13/cns-resolucao-no-466-de-12-dedezembro-de-2012>. Acesso em: 27 jul. 2016.

CAMPOS, Celia M. S.; VIANA, Nildo; SOARES, Cassia B. Mudanças no capitalismo contemporâneo e seu impacto sobre as políticas 
estatais: o SUS em debate. Saúde e Sociedade, São Paulo, v. 24, supl. 1, p. 82-91, 2015.

CAMPOS, Gastão W. S. Cogestão e neoartesanato: elementos conceituais para repensar o trabalho em saúde combinando responsabilidade e autonomia. Ciência \& Saúde Coletiva, Rio de Janeiro, v. 15, n. 5, p. 2.337-2.344, ago. 2010.

CASCAVEL (Prefeitura Municipal). Lei Municipal n. 2.215/1991. Estatuto dos Servidores Públicos Municipais. Cascavel: Prefeitura Municipal de Cascavel, 1991. Disponível em: <www.cascavel.pr.gov.br/portal_servidor/ editais/20150202105538.pdf>. Acesso em: 27 jul. 2016.

CASCAVEL (Prefeitura Municipal). Lei Municipal n. 3.800/2004. Plano de Cargos, Vencimentos e Carreiras do Servidor Público Municipal. Cascavel: Prefeitura Municipal de Cascavel, 2004. Disponível em: <https:// leismunicipais.com.br/al/plano-de-cargose-carreiras-cascavel-pr>. Acesso em: 27 jul. 2016.

CASCAVEL. Portal do Município de Cascavel [website]. História. 2016. Disponível em: <www.cascavel.pr.gov.br/historia.php>. Acesso em: 6 maio 2016.

CORAZZA, Maycon. De volta a Cascavel do futuro. Central Gazeta de Notícias, Cascavel, 21 out. 2015 .

COSTA, Danilo et al. Saúde do trabalhador no SUS: desafios para uma política pública. Revista Brasileira de Saúde Ocupacional, São Paulo, v. 38, n. 127, p. 11-30, 2013.

CRUZ, Luiz C. Dois ex-prefeitos de Cascavel aparecem na lista do TCU. Gazeta do Povo, Curitiba, 20 jun. 2012.

CRUZ, Luiz C. TER-PR cassa mandato de Edgar Bueno, prefeito de Cascavel. Gazeta do Povo, Curitiba, 12 nov. 2013. Disponível em: $<$ www.gazetadopovo.com.br/vida-publica/ dois-ex-prefeitos-de-cascavel-aparecem-nalista-do-tcu-36stldduz4zpskusmookywnym $>$. Acesso em: 14 out. 2016.
GARCIA, Ana C. P. Gestão do trabalho e da educação na saúde: uma reconstrução histórica e política. 2010. $171 \mathrm{fl}$. Tese (Doutorado em Saúde Coletiva) - Instituto de Medicina Social, Universidade do Estado do Rio de Janeiro, Rio de Janeiro, 2010.

HARVEY, David. Condição pós-moderna: uma pesquisa sobre as origens da mudança cultural. 25. ed. São Paulo: Edições Loyola, 2014.

JOUTARD, Philippe. Desafios à história oral do século XXI. In: ALBERTI, Verena; FERNANDES, Tania M.; FERREIRA, Maneta M. (orgs). História oral: desafios para o século XXI. Rio de Janeiro: Editora Fiocruz, 2000. p. 31-45.

KOSTER, Isabella. A gestão do trabalho e o contexto da flexibilização no Sistema Único de Saúde. 2008. 208 fl. Dissertação (Mestrado em Ciências) - Escola Nacional de Saúde Pública Sergio Arouca, Fundação Oswaldo Cruz, Rio de Janeiro, 2008.

LAURELl, Asa C.; NORIEGA, Mariano. Processo de produção e saúde: trabalho e desgaste operário. São Paulo: Hucitec, 1989.

MARTINS, Maria I. C.; MOLINARO, Alex. Reestruturação produtiva e seu impacto nas relações de trabalho nos serviços públicos de saúde no Brasil. Ciência \& Saúde Coletiva, Rio de Janeiro, v. 18, n. 6, p. $1.667-$ $-1.676,2013$.

MARX, Karl. Crítica da filosofia do direito de Hegel. 2. ed. São Paulo: Boitempo, 2010.

MARX, Karl. O capital: crítica da economia política. Livro I. São Paulo: Boitempo, 2013.

MARX, Karl; ENGELS, Friedrich. Manifesto comunista. São Paulo: Boitempo, 1998.

MENDES, Áquilas. A saúde pública brasileira no contexto da crise do Estado ou do capitalismo? Saúde e Sociedade, São Paulo, v. 24, supl. 1, p. 66-81, 2015.

MINAYO, Maria C. S. O desafio do conhecimento. 11. ed. São Paulo: Hucitec, 2008. 
NORIEGA, Mariano. Organización laboral, exigencias y enfermedad. In: LAURELL, Asa C. (org.). Para la investigación de la salud de los trabajadores. Washington: Opas, 1993. p. 167-187.

OLIVEIRA, Francisco. Neoliberalismo à brasileira. In: SADER, Emir; GENTILI, Pablo (orgs.) Pós-neoliberalismo: as políticas sociais e o Estado democrático. 6. ed. Rio de Janeiro: Paz \& Terra, 2003. p. 25-28.

RAMALHO, José R. Movimento sindical e política social. In: SADER, Emir; GENTILI, Pablo (orgs.). Pós-neoliberalismo: as políticas sociais e o Estado democrático. 6. ed. Rio de Janeiro: Paz \& Terra, 2003. p. 125-133.
SANTOS, Ariovaldo O. A nova crise do sindicalismo internacional. In: ANTUNES, Ricardo (org.). Riqueza e miséria do trabalho no Brasil. São Paulo: Boitempo, 2006. p. 447-459.

SILVA, Elizabete V. M.; SILVA, Silvio F. O desafio da gestão municipal em relação à contratação da força de trabalho em saúde. Divulgação em Saúde para Debate, Rio de Janeiro, v. 40, p. 7-12, jun. 2007.

Recebido em 22/01/2016

Aprovado em 15/06/2016 